\title{
Marketing de experiência na era digital: criação de um portifólio bibliográfico e estudo bibliométrico
}

\section{Marketing of experience in the digital age: creation of a bibliographic portifolio and bibliometric study}

\author{
Caroline Lima Della Monica ${ }^{1}$, Eduardo Neto Hack ${ }^{2}$, Renata Bezerra Camacho ${ }^{3}$, Eliane Nascimento Pereira ${ }^{1}$ \\ ${ }^{1}$ Universidade Estadual do Oeste do Paraná - UNIOESTE, Cascavel, PR, Brasil. ORCID: http://orcid.org/0000-0002-4359-5484 \\ 2 Universidade Estadual do Oeste do Paraná - UNIOESTE, Cascavel, PR, Brasil. ORCID: http://orcid.org/0000-0002-9667-6093 \\ ${ }^{3}$ Universidade Estadual do Oeste do Paraná - UNIOESTE, Cascavel, PR, Brasil. ORCID: http://orcid.org/0000-0002-4461-8473 \\ ${ }^{4}$ Universidade Estadual do Oeste do Paraná - UNIOESTE, Cascavel, PR, Brasil. ORCID: http://orcid.org/0000-0003-4285-3215
}

Autor para correspondência/Mail to: Caroline Lima Della Monica, carolcarolinalima@gmail.com

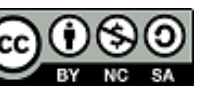

Copyright (c) 2019 Della Monica, Hack, Camacho \& Pereira. Todo o conteúdo da Revista (incluindo-se instruções, política editorial e modelos) está sob uma licença Creative Commons Atribuição-NãoComercial-Compartilhalgual 3.0 Não Adaptada. Ao serem publicados por esta Revista, os artigos são de livre uso em ambientes educacionais, de pesquisa e não comerciais, com atribuição de autoria obrigatória. Mais informações em http://revistas.ufpr.br/atoz/about/submissions\#copyrightNotice.

\begin{abstract}
Resumo
Introdução: $\mathrm{O}$ avanço das Tecnologias da Informação e Comunicação provocou mudanças em todas as áreas da sociedade, como as atividades de marketing e propaganda. A ampliação do acesso à internet e a popularização do uso de equipamentos como computadores pessoais e os smartphones conduziram as empresas para o desenvolvimento do marketing digital. Este estudo visa à construção de um portfólio bibliográfico sobre as transformações digitais que permita compreender como os avanços tecnológicos estão transformando as práticas de marketing e publicidade.

Metodologia: foi utilizada a metodologia ProKnow-C para a construção do conhecimento e a pesquisa foi realizada na base de dados Scopus, na qual foram encontrados 566 artigos com os critérios de busca utilizados, dos quais 221 foram selecionados por estarem alinhados aos objetivos da pesquisa. Aplicando os critérios de seleção e exclusão definidos previamente, 41 estudos compuseram este portfólio bibliográfico. Resultados: a análise bibliométrica evidenciou a heterogeneidade de autores e a concentração de pesquisas nos Estados Unidos e Europa. Conclusão: Com este portfólio, recomenda-se a averiguação das possibilidades de criação de experiências de envolvimento profundo com consumidores nas práticas de marketing e publicidade, em especial com o uso da tecnologia da Realidade Virtual, gerando o marketing de experiência.
\end{abstract}

Palavras-chave: Marketing de Experiência; Transformação Digital; Realidade Virtual; Bibliometria; ProKnow-C.

\begin{abstract}
Introduction: the evolution of Information and Communication Technologies has generate changes in society, such as marketing and advertising activities. The expansion of Internet access and the popularization of the use of equipment like personal computers and smartphones led companies to develop digital marketing. This study aims to build a bibliographic portfolio of digital transformations that allow us to understand how technological advances are transforming marketing and advertising practices.

Method: : it uses the ProKnow-C methodology to build knowledge, and it the search was made at Scopus database. It retrieved 566 articles considering the search strategy used, and 221 articles related to the research objectives were selected. After applying the selection and exclusion criteria, 41 studies made the bibliographic portfolio.

Results: the bibliometric analysis shows the heterogeneity of authors and the concentration of research in the United States of America and Europe. Conclusions: considering the portfolio, it recommends investigating the possibilities of creating experiences of deep involvement with consumers in marketing and advertising practices, especially with the use of Virtual Reality technology, generating experience marketing.
\end{abstract}

Keywords: Marketing of Experience; Digital Transformation; Virtual Reality; Bibliometrics; PrcKnow-C.

\section{INTRODUÇÃO}

$\mathrm{Na}$ era digital, a tecnologia tem papel central na sociedade, assumindo cada vez mais funções na vida das pessoas, bem como permeando todas as áreas das empresas (Schwarzelmüller, 2005; Okada \& Souza, 2011; Secretaria Especial de Comunicação Social, 2016; Porciuncula \& Infante, 2016; Kotler, Kartajaya \& Setiawan, 2017; Lei \& Li, 2017). Além disso, no que se refere à comunicação de marcas com consumidores, é impossível negar a influência das transformações digitais nessa relação (Kotler et al., 2017; Mir \& Rehman, 2013).

$\mathrm{O}$ avanço tecnológico concedeu velocidade para a comunicação e ampliou o alcance da mensagem a qualquer lugar do mundo. Dessa forma, o volume de informações também aumentou exponencialmente, o que criou inúmeras oportunidades para as marcas explorarem seu contato com os consumidores, a fim de melhorar as suas práticas de negócio, obtendo ganhos econômicos e sociais.

Contudo, são raros os estudos que analisam o impacto da transformação digital no marketing, e como o surgimento das novas mídias digitais possibilita a criação de momentos de envolvimento profundo de marcas com consumidores por meio do marketing de experiência (Kerrebroeck, Brengman \& Willems, 2017). 
Neste estudo o objetivo é fazer uma revisão sistemática sobre as transformações digitais e seus impactos nos negócios para constatar o volume de estudos publicados e principais entidades de pesquisa na área e averiguar as pesquisas sobre o marketing de experiência por meio das tecnologias digitais, o que Kotler et al., 2017 definem como criação de experiências de envolvimento profundo com consumidores. Em especial, a pesquisa busca identificar estudos sobre o uso da tecnologia da Realidade Virtual (RV), cuja aplicação em ações de marketing podem promover um diferencial na experiência gerada ao cliente.

Para tanto, utiliza-se a metodologia Knowledge Development Process - Constructivist (ProKnow-C) para estruturar o conhecimento sobre as áreas temáticas e elaborar um portfólio bibliográfico (Afonso, Souza, Ensslin \& Ensslin, 2011). Com o portfólio devidamente selecionado foi possível fazer a análise bibliométrica, quantificando os artigos publicados no período de 2013 a 2017, os autores com maior destaque nas publicações da área, os principais periódicos que publicam sobre o tema e os países que tiveram mais publicações no período.

\section{REFERENCIAL TEÓRICO}

Derivada da palavra em inglês market, que significa mercado, o marketing é a ciência que visa compreender e explorar necessidades da sociedade. Ao considerar que as necessidades humanas datam a partir de sua própria existência, pode-se dizer que o marketing é tão antigo quanto à própria sociedade. A evolução das transações econômicas e sociais, especialmente a partir de 1900, quando houve a modernização dos meios de produção e o aumento populacional e de suas necessidades, tornou as teorias mercadológicas mais robustas (Oliveira, 2012), o que levou à criação de um novo campo de estudos: o marketing.

De acordo com a American Marketing Association (AMA) (2013), "marketing é a atividade, conjunto de instituições e processos para criar, comunicar, entregar e trocar ofertas que tenham valor para clientes, parceiros e a sociedade em geral". Congruente com o conceito, Layton (2015, p. 551) afirma que os estudos de marketing abordam "crenças, comportamentos e práticas sociais e institucionais que surgem das interações de indivíduos, grupos e entidades, participando direta ou indiretamente na criação e entrega de valor social ou econômico, através do intercâmbio voluntário" . Dessa forma, evidencia-se o caráter multidisciplinar do marketing e sua relevância nos processos estratégicos dentro das orga"nizações, assim como no campo de pesquisas sociais aplicadas.

Em tempos contemporâneos, Philip Kotler se destaca como o principal nome dos estudos em marketing. Em trabalhos mais recentes, mostra o avanço pela humanização das atividades de marketing, nas quais o objetivo deixa de ser o lucro a qualquer custo para se voltar ao consumidor, focar em seus valores e emoções para ampliar o relacionamento com o cliente e fazer marcas conversarem com o público (Kotler et al., 2010). Na era digital, Kotler et al.,(2017) propõem o marketing 4.0, com novas maneiras de se fazer marketing e se comunicar mediado pelas Tecnologias da Informação e Comunicação (TICs).

Nesse sentido, o avanço das TICs proporcionou a facilidade de acesso aos recursos tecnológicos, destarte provocou mudanças no modo como pessoas e empresas se relacionam, nas transações comerciais e de trabalho, no entretenimento, entre outras (Okada \& Souza, 2011; Secretaria Especial de Comunicação Social, 2016; Porciuncula \& Infante, 2016; Kotler et al., 2017. Como as atividades de marketing e propaganda também foram fortemente afetadas pelas mudanças tecnológicas e evolução da web (Okada \& Souza, 2011; Secretaria Especial de Comunicação Social, 2016), a ampliação do acesso à internet e a popularização do uso de equipamentos como computadores pessoais e smartphones conduziram as empresas para o desenvolvimento do marketing digital, fazendo-se presente nos locais que seus consumidores frequentam, ainda que sejam virtuais (Okada \& Souza, 2011; Kotler et al., 2017; Comitê Gestor Da Internet no Brasil (CGI) 2017).

No contexto mercadológico, a mudança do perfil do consumidor na era da conectividade, assim como o uso de ferramentas de marketing inovadoras alinhadas com o avanço tecnológico são cada vez mais explorados pelas marcas de maneira a criar experiências diferenciadas para o público, destacado por Kotler et al., 2017 como momentos de envolvimento profundo com o consumidor.

Com novas tecnologias disponíveis e acessíveis ao grande público, o marketing digital utiliza as mídias digitais para se comunicar com os consumidores na era da cibercultura. Kotler et al., (2017, p. 37-38) afirmam que "em um mundo cada vez mais caracterizado pela alta tecnologia, a interação de envolvimento profundo está se tornando a nova diferenciação" e essa interação pode se tornar mais fascinante com o uso de interfaces de alta tecnologia. Assim, a tecnologia é uma importante ferramenta para aprimorar o relacionamento da marca com o cliente por meio do marketing, gerando o marketing de experiência.

Do mesmo modo, Steimer e Conick (2018) evidenciaram que o futuro da experiência do consumidor será marcado pela velocidade, tecnologia e altas expectativas, ou seja, as expectativas do consumidor se adaptam ao mundo digital e esperam das empresas entregas mais rápidas, respostas instantâneas e variedade de opções para atender suas especificidades. O histórico de boas experiências com as empresas elevará as expectativas para com outras marcas, obrigando-as a evoluírem ou serem ultrapassadas. Ademais, tudo indica que esse contexto de contato com o consumidor será marcado pela alta tecnologia, que é responsável por ampliar a variedade de pontos de contato com as marcas. Kotler et al., (2017, p. 44) afirmam que o processo de compra do consumidor na era 
digital ocorre on-line e off-line e tais interações devem "coexistir e serem complementares com o objetivo comum de oferecer uma experiência superior ao consumidor".

Dewey (1950 apud Cabral, 2015) propõe a concepção de experiência associada ao estímulo a sensações. Assim, experiência é concebida como uma ação, e não apenas o ato de receber uma informação. Enquanto a mente é passiva, a experiência é sensorial, com o papel de combinar ideias e sensações. Nesse sentido, o objetivo do marketing de experiência é proporcionar comunicações sensoriais com os prospects a partir de técnicas que estimulem a participação ativa do receptor da mensagem e a interação com a marca. Assim, associa-se a marca aos conceitos desejados e momentos agradáveis memoráveis para o consumidor. Nesse sentido, a partir das transformações digitais, é destacado o potencial das TICs em criar interações entre empresas e consumidores.

O uso de tecnologias pelas empresas tem potencial para facilitar e tornar melhor a vida das pessoas, indo além das criações publicitárias. A Realidade Virtual e Aumentada, a Inteligência Artificial e o Big Data ganham espaço no ambiente de negócios pela possibilidade de serem traduzidos em melhores experiências para os clientes. Segundo Steimer \& Conick, 2018, a inserção da tecnologia em serviços oferecidos pela empresa é, por si só, a criação de experiências memoráveis que farão as marcas ganharem a preferência dos consumidores. Assim, o próprio serviço oferecido pela marca torna-se o diferencial para o seu fortalecimento, cumprindo o mesmo papel que teria uma propaganda direcionada a essa finalidade. Nesse sentido, cita-se o caso da Honda, que lançou um aplicativo de realidade aumentada que permite ao usuário observar a mecânica da moto e o funcionamento do motor, o que é um diferencial útil ao cliente que adquiriu seu produto. Esse cliente valoriza o serviço oferecido pela Honda e cria memórias em relação à marca Honda, além de formar expectativas em receber serviços tão úteis quanto esse no seu contato com outras marcas (tem aplicativo..., 2018).

A proposta é utilizar o potencial tecnológico para proporcionar experiências personalizadas e inigualáveis para o consumidor, e não apenas um conteúdo publicitário intrusivo, de maneira a formar uma experiência memorável para o cliente.

\section{MÉTODOS}

Trata-se de uma pesquisa descritiva, pela forma que apresenta os dados e os resultados obtidos, sendo de natureza mista, pois envolve as abordagens qualitativa e quantitativa (Gil, 2008). Utiliza as técnicas de revisão bibliográfica e bibliometria, baseada na metodologia ProKnow-C , que foi validada por Afonso et al., 2011, e orienta a estruturação do conhecimento com um portfólio bibliográfico visando identificar as pesquisas mais relevantes das áreas temáticas selecionadas. Para suporte da seleção e classificação dos artigos do portfólio, foi utilizado o software livre StArt (Fabbri et al., 2016), que possibilita a criação de um protocolo de pesquisa com critérios de inclusão e exclusão de artigos, assim como a classificação dos artigos selecionados em muito alto, alto, baixo e muito baixo de acordo com o alinhamento deles com os objetivos da pesquisa. Findada a primeira seleção, os dados são extraídos em planilha do Excel para análise bibliométrica. 


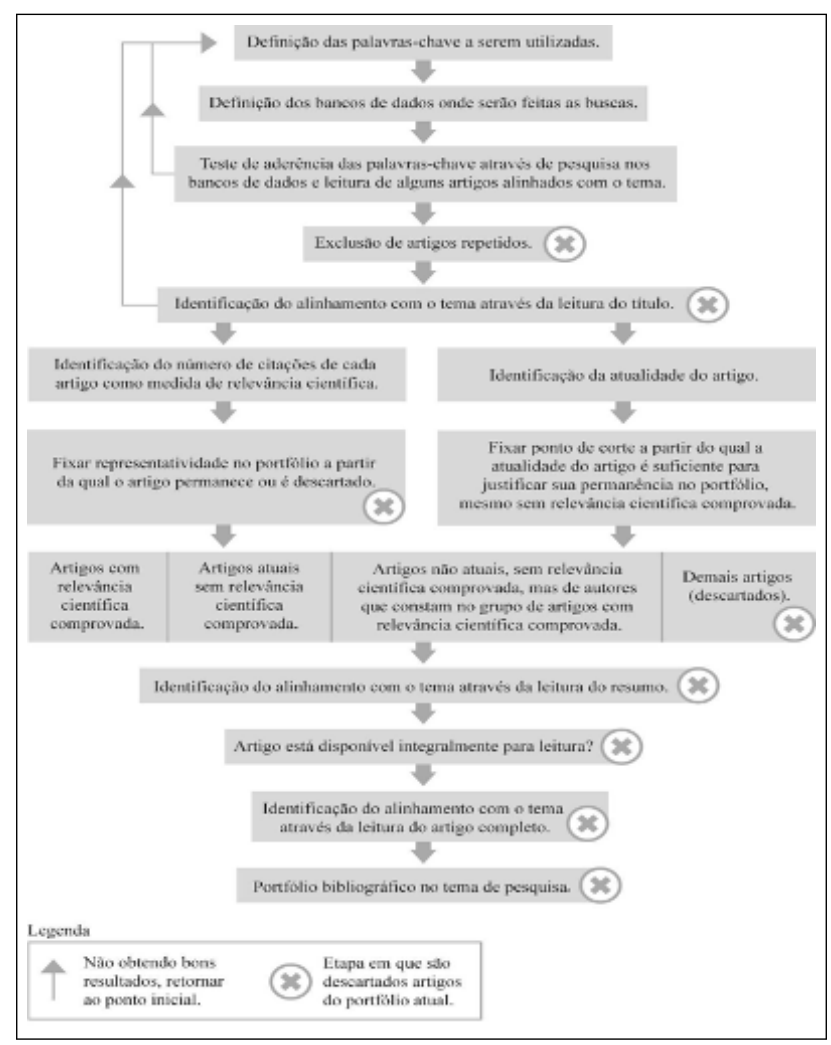

Figura 1. Fluxograma da metodologia ProKnow-C Fonte: Afonso et al. (2011)

Conforme o esquema acima, a primeira fase da pesquisa consiste em determinar as palavras-chaves que serão utilizadas para a busca nas temáticas desejadas. Com os resultados, são verificadas as palavras-chaves em relação à aderência aos objetivos de pesquisa e, se necessário, fazem-se ajustes. Isto posto, definiu-se a base de dados Scopus devido ao seu reconhecimento na comunidade científica e compatibilidade com o software StArt. Dentro da base foram classificados apenas artigos científicos publicados de 2013 a 2017 nos idiomas inglês, português e espanhol. O resultado da pesquisa é extraído da base para o software StArt e se procede com a seleção dos artigos pela consistência do título com o tema de pesquisa.

O passo seguinte é a verificação da relevância científica do artigo. Nessa fase utilizou-se uma planilha do Excel. O método considera o número de citações como forma de reconhecimento da comunidade científica, obtendo essa informação por meio do Google Acadêmico. Contudo, os autores destacam que existem particularidades de acordo com o tema de pesquisa, podendo ocorrer oscilações na quantidade de artigos disponíveis e na quantidade de citações desses artigos. Portanto, cabe ao pesquisador realizar uma análise crítica de cada situação. A recomendação é que seja feito o cálculo da "representatividade de cada artigo perante ao banco de artigos completo em termos do número de citações" (Afonso et al., (2011, p. 07))com sugestão do ponto de corte em torno de 85 por cento. Feito isso, Afonso et al., 2011 avaliaram estudos com relevância científica não confirmada por meio do tempo de publicação. Aqueles publicados em menos de dois anos foram reclassificados para leitura do resumo, enquanto os que tinham mais de dois anos só foram selecionados se tivessem autoria dos principais autores do tema de acordo com o portfólio. Neste estudo, estabeleceu-se como critério adicional para determinar a relevância científica dos artigos as publicações que possuem fator de impacto no Journal Citation Reports (JRC).

O próximo passo é a leitura dos resumos para verificar o alinhamento dos artigos com o tema de pesquisa, ou seja, a comunicação de marcas com consumidores em forma de publicidade, propaganda e/ou marketing. Com o resultado dessa fase, define-se o banco de autores que irão compor o portfólio bibliográfico. Em seguida, descartam-se os artigos cujo texto integral não está disponível e procede-se com a leitura integral dos artigos selecionados para verificar o alinhamento com o tema da pesquisa e determinar aqueles que continuarão compondo o portfólio bibliográfico. Neste estudo, não será feita a última fase do método, que é a leitura integral dos artigos, pois o objetivo deste trabalho é a análise bibliométrica para quantificar os artigos encontrados dentro do tema, as principais instituições que pesquisam o assunto, os países de origem, bem como os autores que tiveram mais destaque. Assim, com o portfólio selecionado, poder-se-á proceder com as leituras integrais com objetivo de fazer a revisão sistemática sobre o tema.

Espera-se que, ao aprofundar os estudos neste portfólio bibliográfico, seja possível compreender as transformações das mídias na era digital, caracterizar o contexto em que a realidade virtual surge como ferramenta de marketing, como tem sido utilizada, e identificar as principais problemáticas dos temas pesquisados, assim como evidenciar 
lacunas de pesquisas. Com isso, é possível conceituar o marketing de experiência na era digital e identificar as possibilidades para a criação de momentos de envolvimento profundo com o consumidor e explorá-lo utilizando a realidade virtual como ferramenta de marketing.

\section{RESULTADOS}

Com o planejamento definido com base na metodologia ProKnow-C, iniciou-se o processo de pesquisa das palavras-chave. O Quadro 1 apresenta as palavras-chave utilizadas para este estudo, cujo teste de aderência foi realizado inicialmente pelas grandes áreas temáticas e então ampliada à variedade de palavras-chave para maior eficiência na busca por artigos relevantes ao objetivo desta pesquisa.

No processo de seleção das palavras o objetivo foi encontrar estudos sobre as transformações digitais no marketing, de forma a identificar quais mídias foram pesquisadas e como foram utilizadas para gerar o marketing de experiência. Por essa razão, as palavras abordaram os grandes temas: transformação digital, novas mídias e marketing de experiência.

\begin{tabular}{|c|c|c|}
\hline Área temática & Palavras-chave & Keywords \\
\hline Transformação digital & $\begin{array}{l}\text { cibercultura; cultura digital; era di- } \\
\text { gital; mundo digital; transformação } \\
\text { digital }\end{array}$ & $\begin{array}{l}\text { digital culture; digital age; digital } \\
\text { world; digital transformation }\end{array}$ \\
\hline Novas mídias & $\begin{array}{l}\text { novas mídias; mídias digitais; mí- } \\
\text { dias inovadoras; convergência de } \\
\text { mídias; convergência midiática }\end{array}$ & $\begin{array}{l}\text { New media; digital media; innova- } \\
\text { tive media; media convergence }\end{array}$ \\
\hline Marketing de experiência & $\begin{array}{l}\text { marketing; publicidade; propa- } \\
\text { ganda; marketing de experiência; } \\
\text { experiência de consumo; experiên- } \\
\text { cia do cliente; envolvimento com o } \\
\text { cliente; envolvimento com o consu- } \\
\text { midor; envolvimento com a marca. }\end{array}$ & $\begin{array}{l}\text { publicity; advertising; marketing; } \\
\text { consumer experience; customer } \\
\text { experience; consumer engage- } \\
\text { ment; customer engagement; } \\
\text { consumer involvement; customer } \\
\text { involvement; brand engagement }\end{array}$ \\
\hline
\end{tabular}

Quadro 1. Definição de palavras-chave

Fonte: Elaborado pelos autores (2019).

Foram encontrados 1495 artigos na base de dados Scopus com as palavras-chave (TITLE-ABS-KEY ("digital culture") OR TITLE-ABS-KEY ("digital digital") OR TITLE-ABS-KEY ("digital transformation") OR TITLEABS-KEY ("digital world") OR TITLE-ABS-KEY ("media convergence") OR TITLE-ABS-KEY ("innovative media") OR TITLE-ABS-KEY ("new media") OR TITLE-ABS-KEY ("digital media") AND TITLE-ABSKEY (publicity) OR TITLE-ABS-KEY (advertising) OR TITLE-ABS-KEY(marketing) OR TITLE-ABS-KEY ( "consumer experience") OR TITLE-ABS-KEY ( "customer experience") OR TITLE-ABS-KEY ("consumer engagement") OR TITLE-ABS-KEY ( "customer engagement") OR TITLE-ABS-KEY ( "consumer involvement") OR TITLE-ABS-KEY ("customer involvement") OR TITLE-ABS-KEY ("brand engagement").

O resultado foi refinado dentro da própria base, limitando o ano de publicação de 2013 a 2017 , a fim de ter um panorama atual do assunto nos idiomas inglês, português e espanhol. Foram excluídas publicações dos tipos: "article in press", "book", "editorial", "note" e "letter"; mantendo-se os arquivos dos tipos: "article", "conference paper", "book chapter", "review", "short survey", "conference review" e "erratum". Dessa forma, foram encontrados 583 artigos, dos quais 17 duplicados foram descartados, resultando em 566 artigos para análise.

A seguir foi iniciada a seleção dos títulos alinhados com o tema de pesquisa, abordando a influência da cibercultura nos meios de comunicação de marcas com consumidores; novas mídias para comunicações publicitárias; e o marketing de experiência de empresas com seus consumidores. Nessa fase, notou-se a necessidade de avaliação conjunta dos resumos, pois não raro, os títulos não evidenciavam o conteúdo dos estudos. Assim, restaram 221 estudos e foi feita a extração dos resultados do software para o Excel para realizar as análises bibliométricas.

Os artigos selecionados são de autoria e coautoria de 504 pesquisadores, dos quais 14 tiveram duas publicações, o que retrata pouca polarização nas autorias. Quanto à tipologia textual, foram 139 artigos publicados em periódicos; 28 capítulos de livros; 47 artigos publicados em anais de eventos; e sete reviews, todos disponíveis no idioma inglês. 


\begin{tabular}{|c|c|c|}
\hline $\begin{array}{c}\text { Total de artigos } \\
\text { encontrados }\end{array}$ & $\begin{array}{c}\text { Estudos aderentes ao } \\
\text { tema de pesquisa }\end{array}$ & Autores com duas publicações \\
\hline 556 & 221 & $\begin{array}{c}\text { Chen, S; Choi, M.-W.; Earnshaw, R.; Elias, H.; } \\
\text { Kerdvibulvech, C.; Kim, K.Y.; Komodromos, M.; Kontu, H.; } \\
\text { Li, Q.; Li, W.; Pophal, L.; Vecchi, A.; Xu, Y.; Zhang, C. }\end{array}$ \\
\hline
\end{tabular}

Quadro 2. Resultados preliminares dos estudos encontrados Fonte: Elaborado pelos autores (2019).

Em relação ao ano de publicação dos estudos selecionados pela aderência do tema ao objetivo desta pesquisa, ainda sem considerar a relevância científica, nota-se o aumento do volume de publicações nos últimos 5 anos, com exceção do ano de 2014: foram 32 em 2013; 2014 (31); 2015 (38); 2016 (56); e 2017 (64).

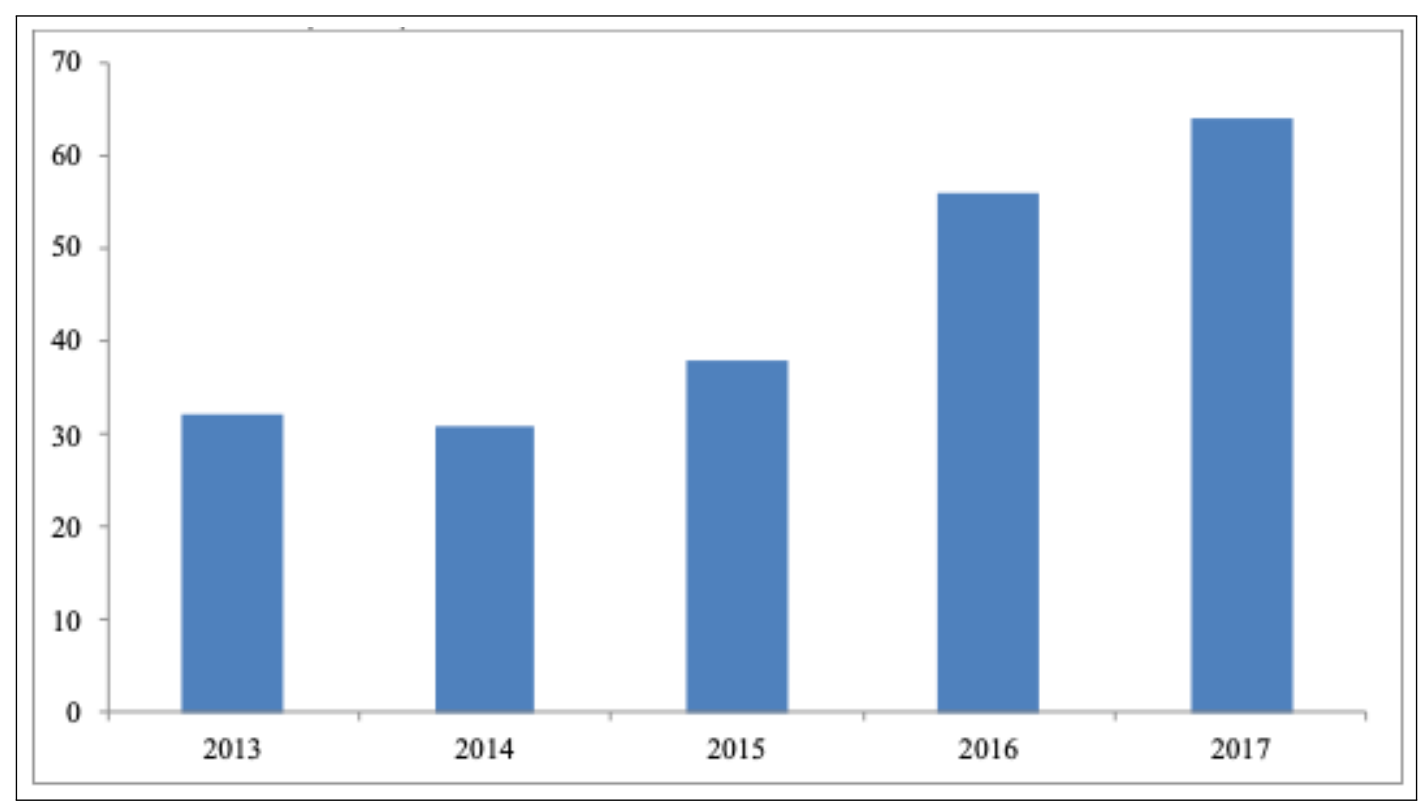

Figura 2. Ano das publicações

Fonte: Elaborado pelos autores (2011).

Para a confirmação da relevância científica dos estudos encontrados, foi verificada a quantidade de citações no Google Acadêmico de cada estudo, assim como o fator de impacto das publicações científicas. Nessa fase, 136 estudos tinham ao menos uma citação e a média de citações foi 12, assim, considerando a representatividade de $85 \%$, os artigos que compõem o portfólio devem ter ao menos 10 citações. Dos publicados em periódicos científicos com fator de impacto no JCR, foram 64 estudos.

Seguindo os critérios estabelecidos para a elaboração deste portfólio, foram excluídos 73 estudos pela inexistência de citação e de fator de impacto; somados a 91 estudos com menos de 10 citações; e 24 estudos excluídos por não terem fator de impacto, restando 33 estudos para análise. Dos excluídos, oito foram novamente selecionados por terem sido publicados nos últimos dois anos (2016 e 2017) em periódicos com fator de impacto e classificados com alto grau de alinhamento com o objetivo desta pesquisa. Dessa maneira, mantiveram-se no portfólio 41 estudos. 


\begin{tabular}{|l|l|l|}
\hline \multicolumn{2}{|l|}{ Quantidade de estudos } & 41 \\
\hline \multirow{4}{*}{ Ano de publicação } & 2013 & 06 \\
\cline { 2 - 3 } & 2014 & 04 \\
\cline { 2 - 3 } & 2015 & 09 \\
\cline { 2 - 3 } & 2016 & 09 \\
\cline { 2 - 3 } & 2017 & 13 \\
\hline \multirow{4}{*}{ Tipo de publicação } & Artigo & 39 \\
\cline { 2 - 3 } & Review & 02 \\
\hline \multirow{4}{*}{ Principais países de publicação } & EUA & 22 \\
\cline { 2 - 3 } & Inglaterra & 11 \\
\cline { 2 - 3 } & Holanda & 05 \\
\cline { 2 - 3 } & Itália & 01 \\
\cline { 2 - 3 } & Nova Zelândia & 01 \\
\cline { 2 - 3 } & Coreia do Sul & 01 \\
\hline
\end{tabular}

Quadro 3. Composição de portifólio

Fonte: Elaborado pelos autores (2019).

Com o mesmo comportamento de toda a amostra selecionada, nota-se maior volume de publicações nos últimos dois anos. Quanto à tipologia de publicações, 95 \% são artigos publicados em periódicos científicos, devido ao critério de seleção de publicações com fator de impacto JRC, apenas dois são reviews, contudo também com publicação científica.

Como parte subsequente da análise da composição do portfólio, averiguou-se os periódicos com maior volume publicações dentro do tema. Os países com destaque nas publicações sobre o tema são Estados Unidos e Inglaterra, seguidos por Holanda, Itália, Nova Zelândia e Coreia do Sul, os quais se assemelham por serem considerados países de economias desenvolvidas (Nova Zelândia e Coreia do Sul).

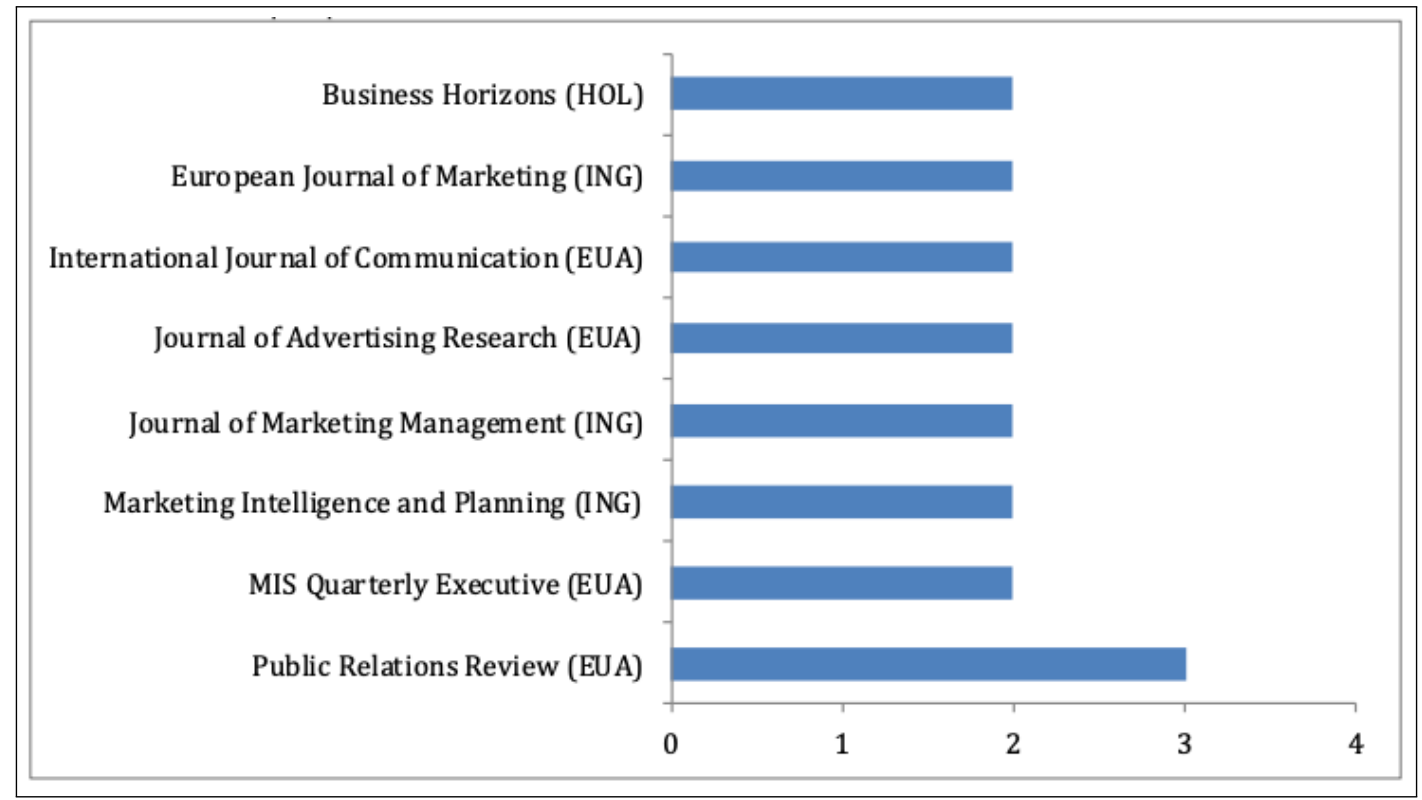

Figura 3. Principais periódicos

Fonte: Elaborado pelos autores (2019).

Ao todo foram 32 periódicos científicos, dos quais oito tiveram pelo menos duas publicações de artigos e são originários dos Estados Unidos, Inglaterra e Holanda.

\section{CONCLUSÕES}

Em um mundo onde as transformações digitais assumiram importante papel na vida e comportamento das pessoas, é relevante analisar de que forma ocorreram essas mudanças e como as novas TICs influenciaram no segmento de marketing e publicidade.

Considerando o grande volume de informações acessíveis na era digital, esta pesquisa buscou oferecer um panorama atual sobre os impactos das TICs e novas mídias na publicidade e no marketing por meio da elaboração de um portfólio bibliográfico cientificamente relevante. Para tanto, utilizou-se a metodologia ProKnow-C para 
estruturar o conhecimento sobre as áreas temáticas com a elaboração de um portfólio bibliográfico (Afonso, Souza, Ensslin \&, Ensslin, 2011) e dentro da base de dados Scopus, devido ao seu reconhecimento pela comunidade científica e grande volume de trabalhos encontrados dentro da temática proposta. Dessa forma, foi possível fazer a análise bibliométrica com os artigos selecionados e quantificar o volume de artigos publicados no período de 2013 a 2017, os principais autores da área, os principais periódicos que publicaram sobre o tema, bem como os países em destaque nas publicações do período selecionado. Após a aplicação dos critérios de seleção e exclusão, resultaram 41 estudos sobre temas relacionados às transformações digitais no marketing, às novas mídias e ao marketing de experiência na era digital, contudo, não foi encontrado acerca da aplicação da Realidade Virtual ao marketing.

Os resultados mostraram que as pesquisas sobre as transformações tecnológicas na publicidade e marketing cresceram em número de publicações nos últimos cinco anos e são pouco polarizadas entre os autores, e sim concentradas em publicações de países europeus e dos Estados Unidos.

Ademais, há como resultado a contribuição para a literatura empírica da metodologia ProKnow-C, com uma experiência na sua aplicação. No que tange ainda ao método de pesquisa ProKnow-C, verificou-se a necessidade de pequenas adequações na realização desta pesquisa, especificamente em relação à fase de seleção pela leitura dos títulos. Não raro, os títulos dos artigos expressavam alguma das palavras-chave, mas ainda assim não estavam alinhados com os objetivos desta pesquisa ou continham títulos metafóricos. Por vezes, as pesquisas não apresentavam uma palavra-chave, mas seu objetivo era apropriado para compor o portfólio. Portando, neste estudo a leitura dos títulos foi feita conjuntamente com a leitura dos resumos, permitindo a seleção mais assertiva, mas isso resultou em um maior volume de leituras na primeira fase de seleção, além de possivelmente ter mantido artigos que seriam descartados se a avaliação considerasse apenas a leitura do título.

Se comparado com o estudo realizado por Afonso et al., 2011, em que o portfólio bibliográfico foi composto por 13 artigos, esta pesquisa foi consideravelmente maior, chegando a um portfólio composto por 41 artigos, em parte também devido à ampla abrangência do tema em questão. Outro aspecto em relação ao método é a utilização do Google Acadêmico para verificar a quantidade de citações. Nesta pesquisa, o Google não localizou alguns artigos, portanto, outra opção é verificar as citações na própria base de dados pesquisada, neste caso a Scopus, na qual foram encontrados resultados similares ao do Google.

Destarte, espera-se que o portfólio elaborado contribua para a construção de uma revisão sistemática para contextualizar o ambiente do marketing era digital e compreender as possibilidades para o marketing de experiência no contexto das mudanças tecnológicas, especialmente com o uso da Realidade Virtual como ferramenta de marketing.

Como indicações para estudos futuros, recomenda-se a realização da revisão sistemática dos artigos deste portfólio a fim de responder as questões: Como criar experiências de envolvimento profundo com consumidores na era digital? Quais as possibilidades para o uso da realidade virtual como marketing de experiência? Com este portfólio é possível iniciar a leitura dos artigos e verificar qual a compreensão dos autores quanto ao marketing de experiência e ainda verificar como os autores aplicam ou pesquisam a aplicação das mídias inovadoras nas ações de marketing e publicidade? Como objetivo específico, sugere-se identificar quantos artigos do portfólio citam a realidade virtual como ferramenta de marketing e propaganda, gerando o marketing de experiência.

Além disso, recomenda-se pesquisar outras bases científicas ou mesmo eventos com reconhecida relevância nas áreas de publicidade e marketing. Ademais, é possível averiguar a influência das novas mídias em segmentos específicos, assim como a influência de uma determinada mídia, a fim de compreender seu uso e comportamento dos consumidores. 


\section{REFERÊNCIAS}

Afonso, M. H. F., Souza, J. V., Ensslin, S. R., \& Ensslin, L. (2011). Como construir conhecimento sobre o tema de pesquisa? aplicação do processo proknow-c na busca de literatura sobre avaliação do desenvolvimento sustentável. Revista de Gestção Social e Ambiental, 5(2), 47-62.

AmericanMarketingAssociation. (2013). Definition of marketing, approved july, 2013. Recuperado de https://www.ama.org/AboutAMA/Pages/Definition-of -Marketing.aspx.

Cabral, C. C. (2015). Dewey e as relações entre natureza e experiância no ato investigativo. Cognitio-Estudos: Revisa Eletrônica de Filosofia, 12(2), 170-178.

ComitêGestordaInternetnoBrasil. (2017). Pesquisa sobre o uso das tecnologias de informação e comunicação nos domiculios brasileiros: Tic domicílios 2016. São Paulo: Comitê Gestor da Internet no Brasil.

Fabbri, S., Octaviano, F., Silva, C., Di Thommazo, A., Hernandes, E., \& Belgamo, A. (2016). Improvements in the start tool to better support the systematic review process. In 2020 international conference on evaluation and assessment in software engineering (p. 1-5). Recuperado de https:// dl.acm.org/doi/10.1145/2915970.2916013.

Kerrebroeck, H. V., Brengman, M., \& Willems, K. (2017). Factors affecting consumer attitudes and intentions toward user-generated product content on youtube. Virtual Reality, 21, 177-191.

Kotler, P., Kartajaya, H., \& Setiawan, I. (2010). Marketing 3.0: as forças que estão defendendo o novo marketing centrado no ser humano. Rio de Janeiro: Elsevier.

Kotler, P., Kartajaya, H., \& Setiawan, I. (2017). Marketing 4.0: do tradicional ao digital (6a. ed.). Rio de Janeiro: Sextante.

Layton, R. (2015). Marketing, marketing systems, and the framing of marketing history. Journal of Historical Research in Marketing, 7(4), 549-572.

Lei, M., \& Li, L. (2017). Study on the framework of enterprise new media marketing strategy based on internet plus background. Boletiin Técnico, 55(18), 79-85.

Mir, I. A., \& Rehman, K. U. (2013). Factors affecting consumer attitudes and intentions toward user-generated product content on youtube. Management $\&$ Marketing, $8(4), 637-654$.

Okada, S. I., \& Souza, E. M. S. (2011). Estratégias marketing digital na era das buscas. Revista Brasileira de Marketing, 10(1), 46-72. doi: /10.5585/remark.v10i1.2199.

Porciúncula, L., \& Infante, J. (2016). Agendas digitais na américa latina e caribe: boas práticas para aproveitar as oportunidades da economia digital. In Pesquisa brasileira de mídia 2016: hábitos de consumo de mídia pela população brasileira. Brasília, Brasil: Secom, Presidência da República.

Schwarzelmüller, A. F. (2005). Inclusão digital: uma abordagem alternativa. In 4 encontro nacional de ciência da informação (p. 1-15). Recuperado de http://www.cinform-anteriores.ufba.br/vi_anais/docs/ AnnaSchwarzelmuller.pdf

SecretariaEspecialdeComunicaçãoSocial. (2016). Pesquisa brasileira de mídia 2016: hábitos de consumo de mídia pela população brasileira. Brasília: Secom.

Steimer, S., \& Conick, H. (2018). What does the future of customer experience look like? Chicago, Ill., EUA: American Marketing Association. Recuperado de https:// www.ama.org/publications/MarketingNews/Pages/ what-does-future-customer-experience-look-like.aspx.

tem aplicativo..., M. (2018). Moto tem aplicativo com realidade aumentada para uso do manual. TV Globo. Recuperado de http://g1.globo.com/tecnologia/videos/ t/todos-os-videos/v/moto-tem-aplicativo-com-realidade -aumentada-para-uso-do-manual/6626961/.
Como citar este artigo (APA):

(2019). Marketing de experiência na era digital: criação de um portifólio bibliográfico e estudo bibliométrico. AtoZ: novas práticas em informação e conhecimento, 8(2), 8 - 16. Recuperado de: http://dx.doi.org/ $10.5380 /$ atoz.v8i2.65779 